\title{
OPPIDUM. REFLEXIONES ACERCA DE LOS USOS ANTIGUOS Y MODERNOS DE UN TÉRMINO URBANO
}

\author{
OPPIDUM. ON MODERN AND ANCIENT USES OF AN URBAN TERM
}

\author{
IVÁN FUMADÓ ORTEGA*
}

\begin{abstract}
Resumen: La formación de las primeras experiencias urbanas de la Península Ibérica es una de las cuestiones más interesantes de nuestra Protohistoria. Directa o indirectamente relacionadas con este argumento, un número creciente de publicaciones se refieren a los lugares en los que la población se concentró durante este periodo con el término oppidum. El objetivo del presente artículo es ofrecer elementos para una reflexión sobre dicho término, atendiendo a su aparición en las fuentes y a su uso en la literatura arqueológica nacional e internacional. Con ello se pretende contribuir a la creación de un debate sobre la terminología científica aplicada al estudio de la Protohistoria peninsular. Palabras clave: Protohistoria, proceso de urbanización, terminología, historiografía, oppidum
\end{abstract}

\section{INTRODUCCIÓN}

Pocos son los grupos de investigación dedicados al estudio de las diversas sociedades ibéricas y celtíberas que renuncien al uso del término oppidum. Como veremos más adelante, éste es un fenómeno relativamente reciente en la literatura nacional. Sin embargo, a diferencia de lo que ha sucedido en otras escuelas, en la tradición española este uso no ha sido precedido por una definición comúnmente aceptada o, al menos, por un

\footnotetext{
* Fundación Española para la Ciencia y la Tecnología-Zentrale des Deutschen Archäologischen Instituts Berlin. Correo-e: i.fumado. ortega@gmail.com
}

Summary: The urbanisation process in the Iberian Peninsula is one of the most interesting questions of the Iberian Iron Age. An ever growing amount of publications directly or indirectly related with this topic uses the term oppidum referring to those places, where the population was living during the concentration process in this period. The aim of this paper is to pay attention to the uses of this term both in ancient texts and in Spanish and international archaeological literature, in order to gather ideas that can help us to reflect about and debate on such a significant term in the study of the Iron Age in the Iberian Peninsula.

Key words: Protohistory, urbanisation process, terminology, historiography, oppidum

debate. La consecuencia inmediata es la aplicación del término a diversas realidades arqueológicas.

$\mathrm{Si}$ bien existen tácitos acuerdos regionales, las ciudades del Guadalquivir de los ss. VI-V a.C., las de la Meseta norte de los ss. II-I a.C. o las pequeñas fortificaciones del Levante presentan en su cultura material, morfología y significación histórica y cultural suficientes diferencias como para ser identificadas bajo una nomenclatura más específica. Con la calificación de estos yacimientos como oppida, tan sólo acompañada por un adjetivo etnogeográfico en el mejor de los casos, se distorsiona la comprensión de los varios fenómenos urbanos de la Protohistoria peninsular y se dificulta el diálogo entre los grupos de investigación, tanto a nivel nacional como internacional, pues la Oppidaforschung 
atiende, por su parte, a yacimientos cuya tipología (tampoco definida con éxito) no siempre coincide con la que se halla en la Península Ibérica.

El objetivo de este artículo no es aportar una solución a esta cuestión, ya que ésta sólo puede ser fruto de un diálogo científico entre diversas escuelas. Tampoco representa una novedad señalar la existencia de este problema, pues ya ha sido señalada por varios investigadores. Así pues, este artículo aspira tan sólo a reunir, en castellano, una serie de datos mínimos a partir de los cuales reflexionar sobre el término oppidum, sus posibles definiciones, especificidades y límites. Para ello será necesario recordar la etimología y significados del término latino, así como su empleo por parte de Julio César, como primera fuente literaria conservada que hace extenso uso de la palabra. A continuación, se repasarán los inicios de la adopción arqueológica del término por parte de la arqueología francesa de finales del siglo XIX y su extensión a la Oppidaforschung europea. Tras un breve análisis del fenómeno equivalente en la historiografía española durante los años 70 del siglo XX, se incidirá en la pluralidad de realidades arqueológicas que se esconden bajo el mismo término, así como en algunos de los cuestionables lugares comunes que sustentan la mayoría de estos usos. Para finalizar, se recordará el objetivo último del artículo, es decir, la necesidad de realizar un esfuerzo de normativización de las categorías de análisis para el estudio del fenómeno urbano durante la Edad del Hierro peninsular.

\section{OPPIDUM COMO TÉRMINO LATINO}

La etimología del término ha sido discutida como puede comprobarse en las definiciones de varios diccionarios y en la bibliografía que éstas han generado, recogidas por Andreas Boos (1989: 56 notas 15-21). No obstante, ésta parece proceder de las expresiones quod ob pedes est, quod pedibus obest y pedica, lo que haría referencia a un obstáculo en el camino y, por tanto, a una fortificación que impidiera el paso. Pero el término parece haber sufrido, como sucede habitualmente, una transformación diacrónica de su significado. Así, durante los últimos siglos de la República se habría perdido el sentido original de barrera defensiva y estaría más en boga otro moderno, equivalente en ciertos casos al de urbs (Kornemann 1939: 709-714). Así, como aglomeración demográfica de entidad superior a los fora, conciliabula y vici, es como se empleó ya en la Lex Acilia del 123 a.C. (CIL I $\left.{ }^{2}, 583,31\right)$ y en la Lex Agraria del 111 a.C. (CIL I², 585,5). Más adelante siguió empleándose para identificar poblaciones importantes, por oposición a su territorium y ager (Jiménez 1993: 215-219). Un estudio de los textos legales y senatus consulta republicanos, reunidos principalmente a partir de restos epigráficos y por los relatos de Tito Livio (Tarpin 1999: 285-287), muestra que desde las reformas de los Gracos hasta las Guerras Sociales se habría producido dicha evolución semántica, de la que no parece hacerse eco Agustín Jiménez de Furundarena (1993: 215-216) cuando afirma que, según la fuentes latinas: oppidum “...es siempre un tipo concreto de núcleo habitado de gran entidad (...) definiéndose como ciudad amurallada o plaza fuerte, o también como" sedes civitatis, urbs. A partir de entonces, los textos legales evidencian un desarrollo de la terminología referida a los núcleos de hábitat que tiende a hacerse más específica (Tabla 1). Mientras que se puede hallar una definición concreta a la mayoría de términos empleados en estos textos, il est, en revanche, impossible de donner un sens fonctionel ou statutaire aussi précis à oppidum ou uicus (Tarpin 1999: 287). Así, en época altoimperial pasó a usarse de forma genérica para englobar colonias, municipios y prefecturas (cf. Plin. NH. 1.3.7), por oposición a vici, castella y a otros núcleos de hábitat que no habían sido fundados mediante rito inaugural alguno (Tarpin 1999: 288-293). Este acento que desde la óptica antigua se habría puesto en las características religiosas del hábitat, no prestaría atención a la identidad étnica, o de cualquier otro tipo, de la población en cuestión. Los binomios oppidum-urbs u oppidum-civitas nunca habrían servido, pues, para distinguir poblaciones romanas de otras extranjeras ni para diferenciar los hábitats civilizados de los más bárbaros (Tarpin 2000: 27-29). Dicha perspectiva, explícita en Cicerón (Resp. 1.26.41) y en Varrón ( $L L .5 .143)$, explicaría por qué Tito Livio $(42.20 .3 ; 42.36 .1)$ calificó de oppidum a la propia Roma, ya que à ses yeux [los de Tito Livio] oppidum et urbs ne se contredisent pas et peuvent s'appliquer à un même agglomération (Bedon 2003: 242).

Del mismo modo, esta perspectiva antigua hacia los núcleos de hábitat, más semántica y simbólica que física y material, dejaría nuestra actual percepción arqueológica, obsesionada con la arquitectura monumental y militar, en un segundo plano. Se entiende mejor así que Plinio, al margen del tamaño y dispositivos militares de las ciudades de Hispania, hable principalmente de oppida cuando se refiere a ellas (Capalvo 1986: 51-53) y que tanto Polibio (3.90.8) como Lucano (4.224) dejen entender que algunos oppida sólo se fortificaron si pudieron prepararse para la guerra con suficiente antelación. Es en esta dirección en donde apunta 
Tabla 1. Tabla tomada de Michel Tarpin $(1999,285)$, en la que se recogen las apariciones del término oppidum en textos legales romanos durante el periodo republicano. A: Secuencia de fuentes consultadas y comentadas por Tarpin (1999, 281-284); B: Cronología atribuida al texto legal según la fuente consultada; C: Nomenclatura utilizada en dichos textos legales en referencia a diversas realidades poblacionales.

\begin{tabular}{|c|c|c|c|c|c|c|c|c|}
\hline A & B & \multicolumn{7}{|c|}{$\mathrm{C}$} \\
\hline 1 & 359a.C. & & & & & nundinae & & conciliabula \\
\hline 2 & 212a.C. & & & & & fora & & conciliabula \\
\hline 3 & 212a.C. & & & & & fora & & conciliabula \\
\hline 4 & 204a.C. & & & & & fora & & conciliabula \\
\hline 5 & 186a.C. & & & & & fora & & conciliabula \\
\hline 6 & 185a.C. & & municipia & & & & & conciliabula \\
\hline 7 & 182a.C. & & & & & fora & & conciliabula \\
\hline 8 & 180a.C. & & & & & fora & & conciliabula \\
\hline 9 & 169a.C. & & & & & fora & & conciliabula \\
\hline 10 & 123a.C. & oppida & & & & fora & & conciliabula \\
\hline 11 & 111a.C. & oppidum & & & & & uicus & \\
\hline (2b) & Cincius & oppidum & & & & & uicus & \\
\hline 12 & 89-46a.C. & & municipium & colonia & praefectura & forum & & conciliabulum \\
\hline 12 & 89-46a.C. & & municipium & colonia & praefectura & & & \\
\hline 12 & 89-46a.C. & & municipiumfundanum & & & & & \\
\hline 13 & 59-49a.C. & & colonia & municipium & praefectura & forum & & conciliabulum \\
\hline 13 & 59-49a.C. & & colonia & municipium & & & & \\
\hline 14 & Post49a.C. & & municipium & colonia & praefectura & & & \\
\hline 15 & 49-42a.C. & & municipium & colonia & & & & \\
\hline 15 & 49-42a.C. & oppidum & municipium & colonia & praefectura & foum & uicus & conciliabulum \\
\hline
\end{tabular}

igualmente el estudio de Estelle Bedon (2003) sobre la terminología empleada por Tito Livio, quien especifica que hay oppida fortificados (Liv. 28.15.14-15; 35.22.5) y otros que no lo están (Liv. 22.11.4).

Estos recientes estudios justifican por si mismos una revisión de varios lugares comunes frecuentes en la historiografía arqueológica, que conceden a los núcleos romanos el calificativo de ciudad, mientras que, como veremos más adelante, oppidum queda reservado a los centros indígenas. Por otra parte, son varios los autores (Moret 1996: 142; Tarpin 1999: 292 notas 58-59, entre otros) que han llamado la atención sobre otro extendido pero igualmente infundado lugar común, esto es, que la muralla haya sido aceptada desde la época tardorrepublicana como característica principal del oppidum.

Aunque el uso de la palabra es muy antiguo, la primera obra literaria que la recoge, de entre las que se nos han conservado, es, como es bien sabido, De bello gallico de César. Se trata de una narración redactada durante los años 52-51 a.C. tanto por el propio César como, probablemente, por Aulus Hirtius, uno de sus oficiales. En ella se da cuenta de sus campañas militares en las Galias entre los años 58-51 a.C. Esta obra ha sido analizada en varias ocasiones precisamente desde el punto de vista del uso que los autores hacen de la palabra oppidum (Dehn 1951; Boos 1989). En ellas se ha puesto 
de relieve que entre los objetivos de dicha obra figuraba, como no podía ser de otra manera, la promoción política del propio César. Así, el relato fue compuesto pensando en su recepción por parte de los lectores, principalmente en los ciudadanos romanos influyentes. Es por ello que lugares y fenómenos desconocidos para este público fueron descritos con la terminología que éstos conocían. Bajo esta premisa debemos entender que las diversas etnias sometidas por las legiones cesarianas dispusieran de aedificia, castella, vici, urbis y oppida, ya se hallasen en la Galia Narbonense, conquistada por Roma desde el 121 a.C. (Caes. Gall. 7.65.2) o en la indómita Selva Negra (Caes. Gall. 4.19.1-2).

César debió conocer la polisemia de la palabra oppidum (v. supra) y, según el estudio de Andreas Boos (1989), habría jugado con esta circunstancia en su propio beneficio. Es cierto que en algunas ocasiones César lo empleó, junto con urbs, para identificar lugares, hoy en territorio francés, como Bibracta, Alesia (ambas en Borgoña), Avaricum (Centro) o Gergovia (Auvernia), que contaban con una importante actividad comercial, gran significación militar y foro, asamblea y senado, al menos en algunos casos. Pero también lo es que otros muchos oppida por él mencionados carecen de todas de estas características. Oppida son, incluso, los bosques en los que se refugian los britanni (Caes. Gall. 5.21.3). Es verosímil que César hubiese aprovechado la ambivalencia del término, que podía ser entendido como ciudad pero también, en su acepción más antigua, como refugio militar, para magnificar los éxitos de sus campañas militares. Pero también es plausible que, para desilusión de los investigadores, los redactores de De bello gallico no hubiesen aplicado los diversos términos con la precisión que un proyecto político convincente exigiría y, desde luego, no con la misma coherencia con que lo hicieron los redactores de los textos legales estudiados por Michel Tarpin (1999; cf. Tabla 1). Así podría indicarlo que se mencionen hasta 20 urbis en posesión de los biturgos (Caes. Gall. 7.15.1), etnia que con muy poca probabilidad habría desarrollado tal número de ciudades.

Posteriormente otros autores también harán un uso extenso del término al referirse a sucesos bélicos pasados. Es el caso de los elogios militares de Titus Quinctius, de quien Tito Livio (6.29.8-9) dice que tomó en 375 a.C. nueve oppida en nueve días (cf. Tarpin 1999: 282-289), o de Pompeyo Magno, quien enumeró los oppida por él conquistados en la tabula que depositó en el templo de Minerva y en el monumento construido a los pies de los Pirineos (Plin. NH. 3.18). Estrabón (3.4.13) se sumó a la crítica que Posidonio hacía sobre los relatos de Polibio al argumentar que éste último, para ensalzar el prestigio de los generales a su conveniencia, concedía el calificativo de polis a cualquier pueblo grande que éstos hubieran sometido. Como es bien sabido, estos elogios militares seguían unas fórmulas muy estrictas, en las que los convencionalismos tienen un valor más retórico y honorífico que descriptivo. Por ello, los vici, pagi, aedificia u otros términos urbanísticos que no fueran urbis y oppida, de mayor prestigio, no tenían cabida en dichos textos (Tarpin 1999: 290).

Con el paso de los siglos, durante el Bajo Imperio, la palabra oppidum cayó en desuso pese a que las realidades a las que hacía referencia no desaparecieron. Así, a diferencia de civitas o urbs, el término no pervivió en ninguna de las lenguas romances.

En resumen, por todos los problemas asociados a este término latino, entre los que figuran la oscura etimología, su evolución semántica diacrónica, un extenso periodo de polisemia, la compleja crítica textual que debe preceder a la interpretación de cada aparición suya en las fuentes y, por último, su paulatino abandono hasta la desaparición, considero que se deben aceptar las siguientes dos conclusiones: primero, que la palabra oppidum no encuentra en las fuentes clásicas una definición inequívoca que avale su uso científico sin una reflexión explícita previa; y, segundo, que la mayor parte de los usos actuales del término en la literatura arqueológica, al distinguir entre las poblaciones romanas de las indígenas o entre las amuralladas de las no defendidas, parecen contradecir algunos de los usos más extendidos en la Antigüedad.

\section{LOS USOS ARQUEOLÓGICOS DEL TÉRMINO EN LA OPPIDAFORSCHUNG}

En 1867, bajo el impulso de Napoleón III, Jacques Gabriel Bulliot inició las excavaciones arqueológicas en Mont-Beuvray (Borgoña, Francia). Allí se presumía que yacía la antigua Bibracta y, al confirmarse, se prolongaron las campañas durante más de dos décadas, siendo continuadas entre 1897 y 1907 por Joseph Déchelette. En el influyente Manuel d'archéologie de este último, publicado en 1914, ya se defendía sin ambages, que los oppida de los que hablaba César no eran meros refugios fortificados sino auténticas ciudades (Déchelette 1914: 947-948). Se sancionó así una idea, no exenta de orgullo nacional galo, que ha tenido desde entonces gran aceptación pese a su inexactitud.

Joseph Déchelette llegó a esta conclusión tras evaluar algunos yacimientos en territorio francés, como el 
mencionado oppidum de Bibracta, pero también otros como el de Manching (Alta Baviera, Alemania), Velem-Szent-Vid (Vas, Hungría) o Stradonitz (Bohemia Central, República Checa). Las excavaciones de MontBeuvray han sacado a la luz un recinto fortificado de 135 ha, cuya ocupación permanente va desde el s. II a.C. hasta la época augustea, al final de la cual, la población se trasladó a la entonces recién fundada $A u$ gustodunum (Autun). Se documenta, tras la conquista romana de la región y la prolongada estancia en el 52 a.C. del propio Julio César en Bibracta, un desarrollo arquitectónico y urbanístico de la ciudad que incluye la construcción de viviendas de peristilo dotadas de triclinio (Meylan 2008: 22-30), edificios techados con tegulae, un foro, una basílica (Szabó y Tilmár 2008: 55-66) y otras características, que han llevado a hablar de una ciudad galorromana. Ésta es, en la práctica, la más perceptible en el registro arqueológico, pues la fase de finales del s. I a.C. ha arrasado gran parte de los estratos precedentes. Por ello, aunque se hallan materiales muebles fabricados incluso desde el s. V a.C., no se ha podido demostrar una organización compleja del espacio intramuros también para el periodo anterior a la conquista romana (Fleischer 2009).

Por otra parte, en Manching se puede observar un recinto amurallado de 350 ha ubicado en una llanura sin elevaciones importantes en las inmediaciones. Excavado sistemáticamente desde 1955, se ha documentado aquí una concentración poblacional, a partir de principios del s. III a.C., caracterizada por una densidad extremadamente baja. Pese a contar con anterioridad con acuñación de moneda, producción industrial y santuarios urbanos, la fortificación parece haber sido levantada sólo durante la segunda mitad del s. II a.C. Esta imponente construcción parece haber sido pensada para defender no sólo las viviendas de los habitantes, sino también sus campos de cultivo y pastoreo. Todo ello, sin embargo, no evitó el abandono paulatino del oppidum durante el segundo y tercer cuarto del s. I a.C. (Sievers 2003).

Otros enormes recintos fortificados se encuentran también en Stanwick (Yorkshire del Norte, Inglaterra) con 350 ha, Villejoubert (Poitou-Charentes, Francia) con 360 ha, Kelheim (Baja Baviera, Alemania) con 650 ha, Heidengraben (Tubinga, Alemania) con 1662 ha. No obstante, el número de estos grandes yacimientos, cada uno de los cuales presenta problemáticas arqueológicas diversas, es inferior al de otros de entre 50 y 20 ha, más habituales, y muy inferior al de las fortificaciones más pequeñas, menores de 5 ha. Existen, además, grandes diferencias regionales en su distribución, morfología y frecuencia.
Existen oppida, como Tarudunum (Alta Selva Negra, Alemania) con un recinto amurallado de 190 ha, en cuyo interior apenas se ha hallado estructura constructiva alguna (Nierhaus 1983: 45-70). Aunque se ha llegado a pensar que estos enclaves fueron construidos pero no llegaron a ser usados, otros casos, como el de Finsterlohr (Distrito de Main-Tauber, Alemania), con un recinto de 123 ha y un interior igualmente vacío, demuestran, por las varias refacciones y fases constructivas de su muralla (Zürn 1977: 231-264), que éstos tuvieron una vida útil y probablemente cumplieron el cometido para el que fueron creados.

La que fue bautizada como Oppidakultur (Pingel 2007: 166-169) se extendía desde la actual Bohemia, en donde destacaron ya desde el siglo XIX ricos yacimientos como el de Stradonitz, hasta la Europa atlántica, en donde sin embargo no se hallaron este tipo de grandes fortificaciones en altura, sino otras más pequeñas bautizadas por la escuela inglesa como hill-forts (fig. 1). No obstante, desde los años 70 del siglo XX, se han encontrado en esta vasta área otros muchos yacimientos que no encajan en la definición cesariana de oppida y, sin embargo, presentan diversas combinaciones de densidad demográfica, comercio de corta y larga distancia, acuñación de moneda y concentración de procesos productivos (Salač 2012). Ello ha puesto de manifiesto que la ocupación del territorio en la Europa templada no sólo se articulaba mediante oppida, sino que contaba con una amplia variedad de asentamientos principales, amurallados o no, en altura o en llano, con características muy diversificadas (Buchsenschutz 2007). La realidad arqueológica lleva a algunos a pensar que las fortificaciones en altura son más el fruto de crisis en la ocupación del territorio que la culminación de un proceso de urbanización (Salač 2012: 339) y que la fortificación de un asentamiento poco o nada indica sobre el nivel de urbanidad de la sociedad que lo habita (Woolf 1993: 226-231).

Por lo tanto, tras sumar las problemáticas arqueológicas a las procedentes de las fuentes clásicas, anteriormente comentadas, varios autores han cuestionado tanto la coherencia del término Oppidakultur como la utilidad del concepto oppidum en cuanto que categoría de análisis científico (Collis 1984: 6-8). Otros han pasado de la duda a la afirmación, declarando que the oppida do not constitute a useful analytical category as they [los yacimientos así calificados en la literatura arqueológica] are too diverse in scale, form, function and chronology to be susceptible to any but the most general interpretation (Woolf 1993: 223). 


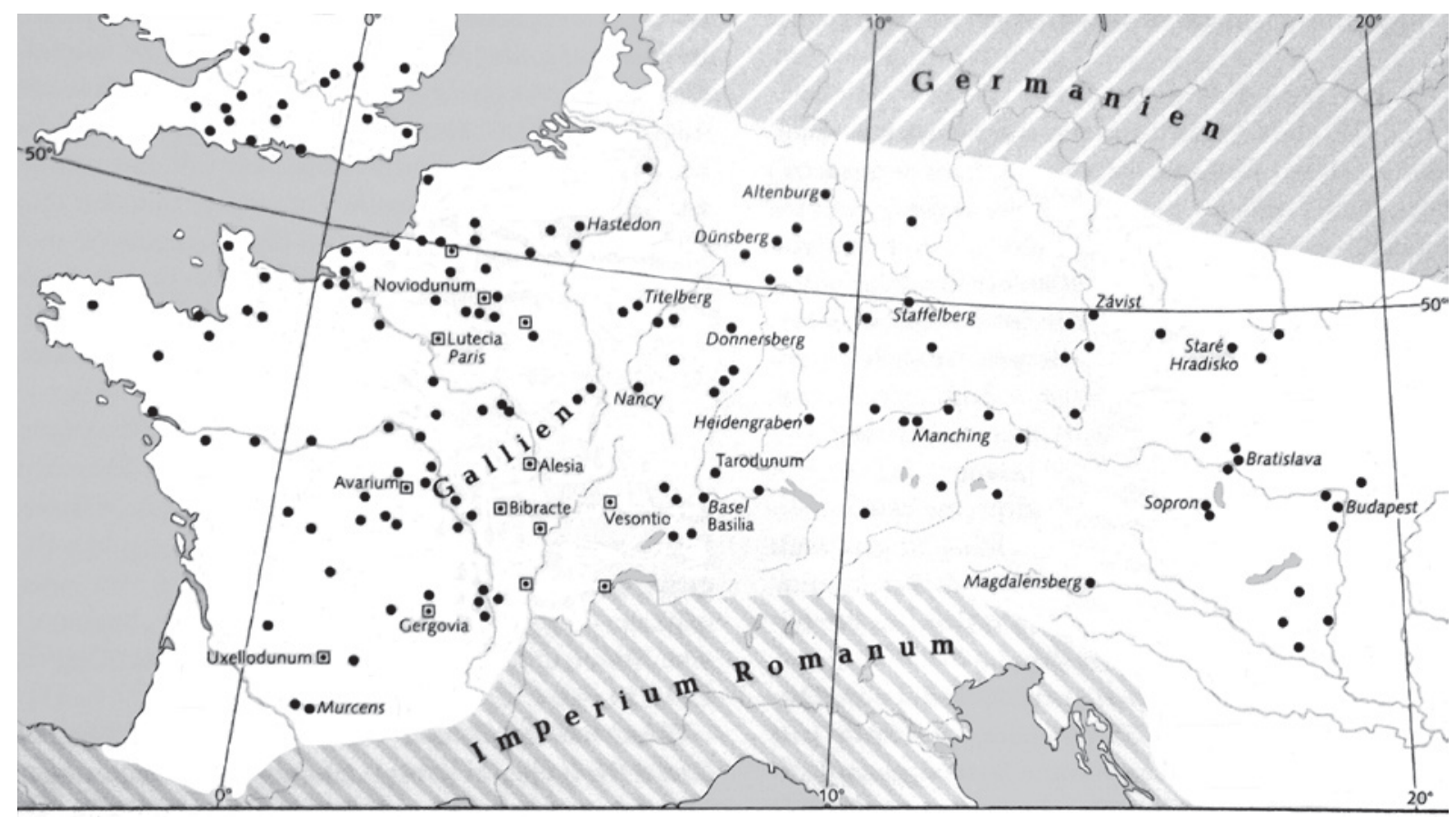

\section{Spätkeltische Oppida nach literarischen und archäologischen Quellen (2./1.Jh.v. Chr.)}

- Oppidum, archäologisch bezeugt

๑ Oppidum, bei Caesar, De bello Gallico. erwähnt und archäologisch bezeugt
Vesontio antiker Name
Paris $500 \mathrm{~km}$

Figura 2. Distribución de los oppida célticos de época tardía mostrada en la Neue Pauly (Pingel 2007, 168), correspondiente a la extensión de la conocida como Oppidakultur. Destaca que, bajo esta voz, se dedica atención a los oppida itálico-romanos y a los celtas de la Europa templada, pero se omite cualquier referencia a los de la Península Ibérica.

\section{LOS USOS DEL TÉRMINO EN LA HISTORIOGRAFÍA ESPAÑOLA}

Los primeros estudios que, partiendo del registro arqueológico, se ocuparon de la Segunda Edad del Hierro en la Península Ibérica focalizaron su atención en la identificación y localización de las etnias que la habitaron. El carácter más o menos urbano de dichas poblaciones no era objeto de discusión, como puede comprobarse en el Essai sur l'art et l'industrie de l'Espagne primitive de Pierre Paris o en la Etnología de la Península Ibérica de Pere Bosch i Gimpera. La identificación étnica de los primeros españoles, el carácter oriental o autóctono de los iberos y su relación con los celtas eran las cuestiones principales que se habían instalado en el debate académico español desde el siglo XIX (Bellón y García 2009: 54-55).

Cuando Adolf Schulten o Manuel Gómez Moreno se referían a lugares como Sagunto (Valencia), Cástulo (Linares, Jaén) o Numancia (Garray, Soria) lo hacían, como la mayoría de sus contemporáneos e inmediatos sucesores, en términos de ciudades. Los yacimientos peninsulares de menor entidad recibían en cambio el calificativo de poblados o estaciones de altura, hillforts por parte de investigadores británicos (Hemp 1929). El término oppidum no es empleado como categoría de análisis ni en la Defensa del Iberismo de Domingo Fletcher Valls ni en La España primitiva de Luis Pericot García. Sí aparece, en cambio, en Los Iberos de Antonio Arribas, cuando se afirma que el establecimiento típico de habitación entre los iberos fue el oppidum fortificado sobre la cumbre de colinas fácilmente defendibles por la naturaleza del lugar (Arribas 1965: 115).

Al margen de esta definición, el uso del término en cuestión hasta los años 70 del siglo pasado es anecdótico (cf. Góngora 1868) y referido mayoritariamente a aquéllos yacimientos que, pese a encontrarse en territorio nacional, podían en principio ser asimilados a aquéllos descritos por César en sus campañas de las Galias (v. supra). Encontramos así artículos sobre los oppida 
de Iruña (Nieto 1958) y de Lastra (Fariña 1973), ambos en Álava, o sobre el oppidum halstattico de Cabezo de Monleón (Caspe, Zaragoza) (Beltrán 1956; 1961). Oppidum se refiere aquí a un yacimiento cuyas primeras fases se dan en el Bronce Final y que, se presumía, había recibido desde entonces fuertes influencias célticas. No obstante, el autor emplea los términos oppidum y poblado indistintamente (Beltrán 1956: 763 766; 1966: 28-35).

La aplicación, también por parte de Antonio Arribas, de este término sólo a yacimientos próximos a la frontera francesa, especialmente a Ullastret (Gerona) (Arribas 1965: 70 y 122), podría ser interpretada en este sentido e indicar una influencia, más o menos consciente, de la arqueología protohistórica francesa (cf. Oliva 1966: 23-28; Querre, Pita y Sarni 1968), pues en esta tradición oppidum se había consolidado desde principios de siglo como, grosso modo, sinónimo de poblado fortificado prerromano.

Pese a ello, el término no es empleado en otras importantes obras, no tan antiguas, como la Contestania ibérica de Enrique Llobregat, de 1972, ni en las comunicaciones del Simposio Internacional Els orígens del món ibèric, de 1977, a excepción de las aportaciones de Yves Solier (1978: 219-220), inscrito en otra tradición de estudios, y la de Martín Almagro Gorbea (1978: 128). Sin embargo, este autor no parece aquí calificar de oppida a todos los yacimientos prerromanos fortificados, sino sólo a aquéllos que, a partir de los ss. VI-V a.C. crecen hasta superar las 10 ó 20 ha. En esta comunicación se cita a otra, por entonces reciente, que resulta ser la primera que, en el ámbito de un Congreso Nacional de Arqueología, se refiere a un yacimiento ibérico (Alarcos, Ciudad Real) calificándolo de oppidum (Prada 1977: 695-704). En efecto, aunque José María Blázquez presentaba asiduamente en estas reuniones periódicas los avances de sus investigaciones en Cástulo, en la decimosegunda edición, de 1971, se refería al yacimiento todavía en términos de ciudad ibérica (Blázquez y Molina 1973) y tampoco empleaba el término de oppidum en la decimotercera edición, celebrada en 1973 (Blázquez y Remesal 1975). Y sin embargo, en la primera monografía que poco después aparecería publicada sobre este yacimiento, se inicia la introducción declarando que el oppidum de Cástulo, como todos los oppida, estuvo amurallado (Contreras 1975: 13). También en este año un joven Barry Cunliffe organizaría en Oxford una reunión titulada Oppida, the beginnigs of urbanisation in bararian Europe (Cunliffe y Rowley 1976) que, probablemente, dadas las futuras colaboraciones que éste emprendió en el sur de España, haya ejercido una cierta influencia en la repentina aceptación y dispersión del término en dicho territorio.

A lo largo de los años 80 el término va efectivamente ganando popularidad. En la I Jornada sobre el Mundo Ibérico celebrada en Jaén en 1985, éste aparece con relativa frecuencia en ponencias procedentes tanto del área catalana como de la Alta Andalucía, pasando por el Levante valenciano. Sin embargo, el significante que nos ocupa amenaza con cobijar tantos significados como autores lo usan: mientras que en el interior de Cataluña un oppidum es un poblado fortificado con importante función militar de época iberorromana (Padró 1987: 52; Junyent 1987: 62), en el área valenciana es un yacimiento que cubre toda la cronología ibérica, de menor entidad que las ciudades Edeta (Sant Miquell de Lliria, Valencia) o Arse (Sagunto, Valencia), que en los casos muy grandes puede llegar hasta las 5 ha pero que en la mayoría de ocasiones ocupa una superficie de entre 3 y 0'5 ha (Bernabeu, et al. 1987: 137-158); por último, en la Alta Andalucía se entiende por oppidum una unidad política y económica básica para la lectura del modelo socioeconómico ibérico (Ruiz et al. 1987: 243). Otra propuesta, presentada al año siguiente, identificaba como oppidum un yacimiento fortificado menor que una ciudad pero más grande que un castellum (Bendala et al. 1986: 126). Sin embargo, otros autores, también centrados en el análisis del fenómeno urbano protohistórico, evitaban el término y preferían seguir hablando de ciudades, lugares centrales (Burillo 1987: 77-98) o fortificaciones, villas y hábitats (Moret 1996: 142 y ss.).

Al final de la década de los 90, el congreso sobre Los Iberos, príncipes de Occidente, supuso una toma de conciencia generalizada del avanzado grado de urbanización alcanzado por las sociedades ibéricas (cf. Bendala 1998), cuestionado hasta no mucho antes (Arribas 1965: 117; Tarradell 1976). Pero ni entonces, ni en el manual de Arturo Ruiz y Manuel Molinos (1993), se ofreció un debate plural sobre el uso científico del concepto oppidum.

Los estudios sobre las sociedades celtíberas han hecho también un profuso empleo de esta palabra, pero sin dedicar tanta atención a su definición (cf. Lorrio 1997: 103-110) como, en cambio, sí ha sucedido con el término castro:

Castro es un poblado situado en lugar de fácil defensa reforzada con murallas, muros externos cerrados y/o accidentes naturales, que defiende en su interior una pluralidad de viviendas de tipo familiar y que controla una unidad elemental de territorio, con 
una organización social escasamente compleja y jerarquizada (Almagro 1994: 15).

Llama la atención que dicha definición sería aceptada por muchos investigadores también para el término oppidum, según escuelas, geografías y cronologías. La mayor parte de las veces, en esta tradición de estudios celtibéricos, oppidum se usa, implícitamente, como sinónimo de ciudad indígena (cf. Berrocal 1994: 189-242; Lorrio 1997: 65-71). Y así, en la bibliografía nacional, cada autor asume, pocas veces de forma explícita, un significado para el término en cuestión que oscila entre un sinónimo de ciudad indígena o una población de inferior categoría, una fortificación grande o pequeña, un lugar central al margen de su grado de urbanización, sin olvidar las varias combinaciones que estos elementos pueden ofrecer.

Pese a ser de sobra conocidos, creo oportuno recordar en este punto dos datos: primero, que prácticamente la mitad de las fortificaciones ibéricas conocidas no superan la media hectárea de extensión, mientras que otras pocas, con abundantes elementos urbanos, sobrepasan las 30 ha (Almagro 1986: 29-31; Moret 1996: 134139); y segundo, que esta diferencia, que va más allá de la lógica de la ocupación del territorio (Moret 2004: 139-140), evidencia diferentes estrategias regionales de habitación (Ruíz y Molinos 1993: 113 y ss.). Además, estrechamente ligado al concepto de oppidum está el debate sobre el fenómeno urbano, que, de forma similar pero con su especificidad propia, adolece igualmente de una cierta indefinición terminológica: Il ne s'agit pas seulment d'un problème de vocabulaire: dévaluer ces concepts, c'est se priver d'un outil d'analyse historique irremplaçable; c'est fondre, contre toute évidence, l'ensemble des socétés protohistoriques dans une sorte de magma proto-urbain consensuel (Moret 2004: 134).

Más recientemente la revista Complutum ha publicado un interesante número especializado en el desarrollo urbano de la Meseta norte durante el I milenio a.C., en donde se puede apreciar la diversidad de posiciones respecto al término que nos ocupa, que van desde el habitual uso implícito como sinónimo de ciudad prerromana (Jimeno 2011: 232), bien relacionado con la presencia de murallas (Sacristán 2011: 208) o con su carácter indígena (Álvarez-Sanchis 2011: 173), hasta una saludable repetición (cf. Burillo 2006: 35-36; 2009: 178-179) de la llamada de atención sobre el debate que requiere la elección de una terminología adecuada al análisis científico de los primeros fenómenos urbanos de la Protohistoria peninsular (Burillo 2011: 278-280). Cabe señalar que este autor indica en dichas citas que oppidum aparece en las fuentes latinas para definir un asentamiento amurallado, sin especificación de su categoría jurídica. Sin embargo, como hemos visto más arriba, es posible defender lo contrario, en virtud de la diferenciación que hacen las fuentes de época tardorrepublicana entre localidades fundadas con rito inaugural, entre las que se encuentran los oppida, y el resto (vici, castella, conciliabula, etc.), al margen de que éstas dispusieran de muralla o no (Tarpin 1999).

Existen excepciones como, entre otras, la mencionada de Francisco Burillo o la de Francisco Gracia:

El poblado fortificado (oppidum) es la agrupación constructiva básica a partir de la cuál se estructura la concepción socioeconómica que define, entre los siglos VII y II a.C., un patrón de control territorial en el marco de la cultura Ibérica en el que se concentran las funciones de centro político y administrativo de un territorio; la organización de la producción económica de las zonas de captación dependientes; los mercados o port-of-trade en los que se lleva a cabo la exportación de materias primas, y la importación de productos manufacturados y comestibles; el establecimiento del control de las rutas de comunicación; y los rasgos ideológicos y religiosos de la comunidad (Gracia 2004: 80).

Sin embargo, el término se ha instalado en la mayor parte de la producción científica nacional del siglo XXI con una forma excesivamente laxa. El éxito con el que lo ha hecho, especialmente en los últimos diez años, se puede comprobar en cualquier buscador bibliográfico y son minoría los investigadores que han renunciado a usarlo. Sin embargo, cabe preguntarse hasta qué punto es lícito su empleo en textos científicos sin referencias a las problemáticas filológicas, arqueológicas e historiográficas más arriba señaladas y hasta qué punto el término vehicula u obstruye la comunicación científica, especialmente hacia el ámbito internacional.

\section{CONCLUSIÓN: POR UNA REVISIÓN DEL TÉRMINO OPPIDUM}

Resulta obvio y probablemente innecesario recordar que un discurso científico se construye mediante un vocabulario lo más inequívoco posible. Para ello, los investigadores nos apoyamos en las definiciones, propias o ajenas, de los términos que usamos. No es tan obvio que, precisamente por este motivo, para dar coherencia y eficacia a nuestras categorías de análisis, resulte interesante atender a las fronteras semánticas, a las zonas de contacto entre diversos significantes y significados. 
El término oppidum ha llegado a ocupar una importancia central en el estudio de la Edad del Hierro peninsular. No obstante, como hemos visto más arriba, dicho término no encuentra una definición inequívoca en las fuentes clásicas. Sin embargo, si además de atender al impreciso uso que le dio Julio César, motivado por sus intereses partidistas, se presta atención a cómo lo usaron los legisladores romanos, el término aparece menos equívoco: un identificador genérico de ciudades, al margen de su origen romano, latino o bárbaro y al margen de si aparecen amuralladas o no, pero que tiene en cuenta su importancia simbólica y jurídica, pues nunca se asoció a poblaciones menores o poco importantes (v. supra).

Pese a ello, la tradición historiográfica ha transmitido una serie de lugares comunes, supuestamente basados en el estudio de dichas fuentes, que los análisis de la última década parecen desmontar, a saber: que con el término se identificaba en época romana a cualquier población que no fuera colonia o municipio romano, a cualquier población al margen de su estatus jurídico o a cualquier población amurallada y/o indígena.

Además de estos usos inexactos, la investigación moderna ha desarrollado otros según diversas escuelas nacionales o regionales. En virtud de éstas, oppidum puede ser una ciudad-estado, un núcleo principal en una fase evolutiva anterior a la ciudad, un núcleo secundario y dependiente de una ciudad coetánea o un pequeño enclave fortificado. En otras palabras, las fronteras semánticas del término oppidum permanecen bien difusas.

Esta disparidad de aplicaciones ha sido ya advertida por la mayoría de los investigadores como un déficit historiográfico. Cuando a éste se le añaden los problemas terminológicos asociados al debate sobre el fenómeno urbano, se comprenden algunas de las dificultades que encuentra la arqueología española en la comunicación entre colegas, no sólo a nivel internacional, así como a nivel interdisciplinar. Tras casi tres décadas de programas europeos, la fuerza de las tradiciones nacionales en Arqueología sigue siendo, en toda Europa, omnipresente. Es por ello que, lamentablemente, problemas científicos comunes sólo pueden encontrar por el momento soluciones nacionales. Pues, no lo olvidemos, desde otras escuelas se viven problemáticas similares (cf. Schreiber 2008) y ni siquiera algunos de los autores más críticos con la vaguedad del término oppidum han querido renunciar al peso historiográfico que indudablemente éste mantiene (cf. Woolf 2000: 118; Collis 2012: 1-12), especialmente en aquellas regiones en donde la mención explícita cesariana parece satisfacer el rigor científico. También cabe señalar que no basta con sustituir unas palabras por otras, como se ha propuesto varias veces (Boos 1989: 73; GringmuthDallmer 1999; Schreiber 2008: 45-47, entre otros) pues, aunque términos como el de Zentralort están libres de connotaciones tradicionales, es su definición lo que resulta clave. Y ésta no puede basarse en una lista de la compra (Osborne 2005: 6-8) de valor universal, que establezca qué características equivalen a qué grados de desarrollo en una escala evolutiva coronada por la ciudad. Las definiciones de los términos elegidos deben de adecuarse al contexto histórico analizado pero, sobre todo, centrarse en los modos de vida de los habitantes del yacimiento en cuestión. Y ello, teniendo presente el objetivo fundamental, que no debe ser otro que analizar y explicar cómo afectan los factores socioeconómicos, políticos, religiosos y geográficos al proceso de concentración poblacional que conocemos como fenómeno urbano.

Las tímidas referencias que últimamente se han manifestado frente a este déficit historiográfico (Moret 2004: 134; Jimeno 2009: 240; Tortosa y Santos 2009: $447)$ no parecen haber sido suficientes como para provocar un verdadero debate. Y sin embargo, desde una óptica peninsular, no debería dejarnos indiferentes, sino hacernos reflexionar, la ausencia de la Península Ibérica en la voz Oppidum de uno de los principales instrumentos para la docencia y la investigación de la Antigüedad en Europa y Norteamérica, es decir, la nueva edición (Neue Pauly) redactada de 1996 a 2003 de la Realencyclopädie der classischen Altertumswissenschaft. El objetivo de este artículo no es otro que contribuir a la formalización de dicho debate.

\section{AGRADECIMIENTOS}

Este trabajo ha sido realizado gracias a la concesión por parte del Ministerio de Educación de una Ayuda a la Movilidad Posdoctoral en Centros Extranjeros, en convocatoria de 2009.

\section{BIBLIOGRAFÍA}

Almagro Gorbea, M. (1978): “La iberización de las zonas orientales de la Meseta". Ampurias 38-40: 93-156.

Almagro Gorbea, M. (1986): "El área superficial de las poblaciones ibéricas", en Los asentamientos ibéricos ante la romanización, pp. 21-34. Madrid, Ministerio de Cultura.

Almagro Gorbea, M. (1994): "Urbanismo de la Hispania "céltica". Castros y oppida del centro y 
occidente de la Península Ibérica", en M. Almagro Gorbea y A. M. Martín (eds.) Castros y oppida en Extremadura, pp. 13-76. Madrid, Universidad Complutense de Madrid.

Álvarez-Sanchis, J. (2011): “Ciudades vettonas". Complutum 22 (2): 147-184.

Arribas, A. (1965): Los Iberos. Barcelona, Aymá.

Bedon, E. (2003): 'Les agglomérations indigènes de la péninsule ibérique chez Tite-Live". Gerión 21: 229-263.

Bellón Ruíz y García Fernández (2009): "Pueblos, culturas e identidades étnicas en la investigación protohistórica de Andalucía, I: de la Restauración a la Guerra Civil", en F. Wulff y M. Álvarez MartíAguilar (ed.) Identidades, culturas y territorios en la Andalucía prerromana, pp. 51-74. Málaga, Universidad de Málaga.

Beltrán Martínez, A. (1956): “La cerámica del poblado halstattico del Cabezo de Monleón (Caspe, Zaragoza)", en $4^{\circ}$ Congreso Internacional de Ciencias Prehistóricas y Protohistóricas, pp. 763-766. Madrid (1954), Zaragoza, Universidad de Zaragoza.

Beltrán Martínez, A. (1961): "Un nuevo Kernos del oppidum hallstattico del Cabezo de Monleón (Caspe)", en $6^{\circ}$ Congreso Nacional de Arqueología, pp. 144-148. Oviedo (1959). Zaragoza, Universidad de Zaragoza.

Beltrán Martínez, A. (1966): "Estudio de los "kernoi" halstatticos de Caspe (Zaragoza, España) y sus relaciones", en $6^{\circ}$ Congresso Internazionale delle Scienze Preistoriche e Protoistoriche, pp. 28-35. Roma (1962). Florencia, Sansoni.

Bendala Galán, M. (1998): "La ciudad entre los iberos. Espacio de poder", en Los Iberos, príncipes de occidente. Saguntum PLAV, Extra 1, pp. 25-34.

Bendala Galán, M., Fernández, C., Fuentes, A. y Abad Casal, L. (1986): “Aproximación al urbanismo prerromano y a los fenómenos de transición y de potenciación tras la conquista", en Los asentamientos ibéricos ante la romanización, pp. 121-140. Madrid, Ministerio de Cultura.

Bernabeu, J., Bonet Rosado, H. y Mata Parreño, C. (1987): "Hipótesis sobre la organización del territorio edetano en época ibérica plena: el ejemplo del territorio de Edeta-Liria", en A. Ruiz y M. Molinos (eds.) Iberos. Actas de las I Jornadas sobre el Mundo Ibérico, pp. 137-158. Jaén (1985). Jaén, Junta de Andalucía.

Berrocal Rangel, L. (1994): “Oppida y castros de la Beturia céltica”, en M. Almagro Gorbea y A. M. Martín (eds.) Castros y oppida en Extremadura, pp. 189242. Madrid, Universidad Complutense de Madrid.
Blázquez, J. M. y Molina, F. (1973): “La necrópolis ibérica de Los Patos en la ciudad de Cástulo (Linares, Jaén)", en $12^{\circ}$ Congreso Nacional de Arqueología, pp. 639-656. Jaén (1971). Zaragoza, Universidad de Zaragoza.

Blázquez, J. M. y Remesal, J. (1975): "Hallazgos en la necrópolis oretana de Cástulo”, en $13^{\circ}$ Congreso Nacional de Arqueología, pp. 639-658. Huelva (1973). Zaragoza, Universidad de Zaragoza.

Boos, A. (1989): “,Oppidum” im caesarischen und im archäologischen Sprachgebrauch. Wiederspruche und Probleme". Acta Praehistorica et Archeologica 21: 53-74.

Buchsenschutz, O. (2007): Les celtes de l'âge du Fer. Paris, Colin.

Burillo Mozota, F. (1987): "Introducción al poblamiento ibérico en Aragón”, en A. Ruiz y M. Molinos, (eds.) Iberos. Actas de las I Jornadas sobre el Mundo Ibérico, pp. 77-98. Jaén (1985), Jaén, Junta de Andalucía.

Burillo Mozota, F. (2006): "Oppida y ciudades estado en el norte de Hispania con anterioridad al 153 a.C.”, en F. Burillo Mozota (ed.) Segeda en su contexto histórico. Entre Catón y Nobilior (195 al 153 a.C.) Homenaje a Antonio Beltrán Martínez, pp. 35-70. Mara, Fundación Segeda.

Burillo Mozota, F. (2009): "Origen y desarrollo de la ciudad en la Celtiberia”, en P. Mateos, S. Celestino, A. Pizzo y T. Tortosa (coord.) Santuarios, oppida y ciudades: arquitectura sacra en el origen y desarrollo urbano del Mediterráneo Occidental, pp. 175-193. Mérida, CSIC.

Burillo Mozota, F. (2011): "Oppida y 'ciudades estado' celtibéricos”. Complutum 22 (2): 277-296.

Capalvo Liesa, A. (1986): "El léxico pliniano sobre Hispania: etnonimia y designación de asentamientos urbanos". Cesaraugusta 63: 49-67.

Collis, J. R. (1984): Oppida. Earliest towns north of the Alps. Sheffield, University of Sheffield.

Collis, J. R. (2012): “Centralisation et urbanisation dans l'Europe tempérée à l'âge du Fer", en S. Sievers y M. Schönfelder (eds.) Die Frage der Protourbanisation in der Eisenzeit. Akten des 34. Kolloquiums der AFEAF, pp. 1-14. Mayo (2010). Bonn, Habelt.

Contreras, R. (1975): “Cástulo en las fuentes”, en J. M. Blázquez (ed.) Cástulo 1, pp. 11-40. Acta Arqueológica Hispánica, 8. Madrid.

Cunliffe, B. y Rowley, T. (eds.) (1976): Oppida: the beginnings of urbanisation in barbarian Europe. Oxford, BAR. 
Dçéchelette, J. (1914): Manuel d'archéologie préhistorique, celtique et gallo-romaine. Paris, Picard.

Dehn, W. (1951): "Die gallischen "Oppida" bei Cäsar". Saalburg-Jahrbuch 10: 36-49.

Fariña, J. (1973): "El oppidum de lastra (Caranca-Alava)", en $12^{\circ}$ Congreso Nacional de Arqueología, pp. 345 347. Jaén (1971). Zaragoza, Universidad de Zaragoza.

Fleischer, F. (2009): "Siedlungswandel im Oppidum Bibracte: Romanisierung und Urbanisierung. Kelten am Rhein, 1". Akten des dreizehnten Internationalen Keltologiekongresses, pp. 85-100. Bonn (2007), Mainz, Philipp von Zabern.

Góngora Martínez, M. (1868): Antigüedades prehistóricas de Andalucía. Madrid, C. Moro.

Gracia Alonso, F. (2004): "Datos para el análisis del concepto de espacio público en los oppida ibéricos: templos, edificios comunitarios y almacenes", en Des Ibères aux Vénètes, pp. 79-111. Roma, ÉFR.

Gringmuth-Dallmer, E. (1999): "Methodische Überlegungen zur Erforschung zentraler Orte in ur- und frühgeschichtliche Zeit”, en S. Moździoch (ed.) Centrum i zaplecze we wczesnośredniowiecznej Europie Środkowej, pp. 9-20. Breslavia, WERK.

Hemp, W. J. (1929): "Three Hill-Forts in Eastern Spain”. Antiquity 10 (3): 188-194.

Jiménez de Furundarena, A. (1993): "Precisiones sobre el vocabulario latino de la ciudad: el término oppidum en Hispania". Hispania Antiqua 17: 215-226.

Jimeno Martínez, A. (2009): "Intervención en la Mesa Redonda del 3.11.2005”, en P. Mateos, S. Celestino, A. Pizzo, y T. Tortosa (coord.) Santuarios, oppida y ciudades: arquitectura sacra en el origen y desarrollo urbano del Mediterráneo Occidental, pp. 239-240. Mérida, CSIC.

Jimeno Martínez, A. (2011): "Las ciudades celtibéricas de la Meseta Oriental”. Complutum 22 (2): 223-276.

Junyent Sánchez, E. (1987): “El poblamiento ibérico en el área ilergeta", en A. Ruiz y M. Molinos (eds.) Iberos. Actas de las I Jornadas sobre el Mundo Ibérico, pp. 57-66. Jaén (1985). Jaén, Junta de Andalucía.

Kornemann, E. (1939): “Oppidum”, en RE 18 (1), pp. 708-725.

Lorrio, A. J. (1997): Los celtiberos. Madrid, Universidad Complutense de Madrid y Universidad de Alicante.

Mateos, P., Celestino Pérez, S., Pizzo, A. y Tortosa Rocamora, T. (coord.) (2009): Santuarios, oppida y ciudades: arquitectura sacra en el origen y desarrollo urbano del Mediterráneo Occidental. Mérida, CSIC.

Meyland, F. (2008): "Les influences romaines dans l'architecture et l'urbanisme: apport des fuilles anciennes", en L. Dhennequin, J. P. Guillaumet y M. Szabó (eds.) L'oppidum de Bibracte (Mont Beuvray, France). Bilan de 10 annees de recherches (1996-2005), pp. 22-30. Acta Archeologica Academiae Scientiarum Hungaricae 59.

Moret, P. (1996): Les fortifications ibériques de la fin de l'Âge du Bronze à la conquête romaine. Madrid, Casa Velázquez.

Moret, P. (2004): "Premières formes d'urbanisme dans l'Ibérie du second Âge du Fer", en Des Ibères aux Vénètes, pp. 133-157. Roma, ÉFR.

Nierhaus, R. (1983): “Zur literarische Überlieferung des Oppidums Tarodunum", en H. Schmid (ed.) Kelten und Alemannen im Dreisamtal. Veröffentlichung des Alemannischen Instituts Freiburg, 49. Bühl, Konkordia.

Nieto Gallo, G. (1958): El oppidum de Iruña. Vitoria, Consejo de Cultura de la Excma. Diputación Foral de Álava.

Oliva Prat, M. (1966): "Las fortificaciones de la ciudad prerromana de Ullastret (Gerona, España)", en $6^{\circ}$ Congresso Internazionale delle Scienze Preistoriche e Protoistoriche, pp. 23-28. Roma (1962). Florencia, Sansoni.

Osborne, R. (2005): "Urban sprawl: what is urbanization and why does it matter?", en R. Osborne y B. Cunliffe (eds.) Mediterranean urbanization 600800 BC, pp. 1-16. Oxford, British Academy.

Padró Parcerisa, J. (1987): "El poblamiento ibérico en el interior de Cataluña”, en A. Ruiz y M. Molinos (eds.) Iberos. Actas de las I Jornadas sobre el Mundo Ibérico, pp. 35-56. Jaén (1985). Jaén, Junta de Andalucía.

Pingel, V. (2007): “Oppidum”, en Brill's New Pauly 10: 166-169.

Prada Junquera, M. (1977): "Las esfinges oretanas del oppidum de Alarcos", en $14^{\circ}$ Congreso Nacional de Arqueología, pp. 695-704. Vitoria (1975). Zaragoza, Universidad de Zaragoza.

Querre, J., Pita Merce, R. y Sarny, H. (1968): “El “Oppidum" ilergete de Punta de Calvari, en Granja de Escarp (Lérida)", en Noticiario Arqueológico Hispánico 10-12, pp. 124-130.

Ruíz Rodríguez, A. et al. (1987): "El poblamiento ibérico en el Alto Guadalquivir", en A. Ruiz y M. Molinos (eds.) Iberos. Actas de las I Jornadas sobre el Mundo Ibérico, pp. 239-256. Jaén (1985). Jaén, Junta de Andalucía.

Ruíz Rodríguez, A. y Molinos, M. (1993): Los Iberos. Análisis arqueológico de un proceso histórico. Barcelona, Crítica. 
Sacristán de Lama, J. D. (2011): "El urbanismo vacceo". Complutum 22 (2): 185-222.

Salač(2012): “Les oppida et les processus d'urbanisation en Europe centrale", en S. Sievers y M. Schönfelder (eds.) Die Frage der Protourbanisation in der Eisenzeit. Akten des 34. Kolloquiums der AFEAF, pp. 319-346. Mayo (2010), Bonn, Habelt.

Schreiber, S. (2008): "Das keltische Oppidum zwischen Protostadt und Stadt", Ethnographisch-Archäologische Zeitschifft 49: 25-56.

Sievers, S. (2003): Manching: Die Keltenstadt. Stuttgart, Theiss.

Solier, Y. (1978): "La culture ibéro-languedocienne aux VI-V siècles”. Ampurias 38-40: 211-264.

Szabó, M. y Tilmár, L. (2008): "Édifices et lieux publics", en L. Dhennequin, J. P. Guillaumet y M. Szabó (eds.) L'oppidum de Bibracte (Mont Beuvray, France). Bilan de 10 annees de recherches (19962005), pp. 55-66. Acta Archeologica Academiae Scientiarum Hungaricae 59.

Tarpin, M. (1999): “Oppida ui capta, uici incensi... Les mots latins de la ville". Latomus 58 (2): 279-297.

Tarpin, M. (2000): "Urbs et oppidum. Le concept urbain dans l'Antiquité romaine", en V. Guichard,
S. Sievers y O. H. Urban (eds.) Les processus d'urbanisation à l'âge du Fer. Bibracte, 4: 27-30.

Tarradell, M. (1976): "Las ciudades romanas en el Este de Hispania", en Ciudades Augusteas de Hispania: bimilenario de la Colonia Cesaraugustea, pp. 289313. Zaragoza, Universidad de Zaragoza.

Tortosa Rocamora, T. y Santos Velasco, J. (2009): "Cuestiones finales sobre la arqueología de la ciudad y de lo sagrado en el Mediterráneo occidental prerromano y romano", en P. Mateos, S. Celestino, A. Pizzo, y T. Tortosa (coord.) Santuarios, oppida $y$ ciudades: arquitectura sacra en el origen y desarrollo urbano del Mediterráneo Occidental, pp. 447-450. Mérida, CSIC.

Woolf, G. (1993): "Rethinking the oppida". Oxford Journal of Archaeology 12 (2): 223-234.

Woolf, G. (2000): "Urbanization and its discontents in Early Roman Gaul", en E. Fentress (ed.) Romanization and the city. Creations, transformations and failures, pp. 115-132. Journal of Roman Archaeology, Suppl. 38.

Zürn, H. (1977): "Grabungen im Oppidum von Finsterlohr". Fundbericht Baden-Württenberg 3: 231-264. 